\title{
Adubação residual na produção de mudas clonais de eucalipto
}

\author{
Pedro Henrique Alcântara de Cerqueira1', Gileno Brito de Azevedo², Anderson Marcos de Souza¹, Glauce Taís de Oliveira Sousa Azevedo \\ 1 Universidade de Brasília, Faculdade de Tecnologia, Asa Norte, C P 04357, CEP 70904-700, Brasília, DF, Brasil \\ 2Universidade Federal de Mato Grosso do Sul, Rod MS 306, Km 105, C P 112, CEP 79560-000, Chapadão do Sul, MS, Brasil
}

"Autor correspondente:
pedrohenrique.alc@gmail.com

Termos para indexação:

Fertirrigação

Mudas de viveiro

Efluentes

Index terms:

Fertigation

Nursery

Effluents

Histórico do artigo:

Recebido em 31/05/2015

Aprovado em 01/05/2017

Publicado em 30/06/2017

doi: 10.4336/2017.pfb.37.90.934

\begin{abstract}
Resumo - Apesar do desenvolvimento técnico e operacional dos viveiros clonais ao longo dos anos, poucos estabelecimentos apresentam sistemas de reaproveitamento de resíduos e efluentes do processo produtivo. O objetivo dessa pesquisa foi avaliar o uso de efluente oriundo de minijardim clonal como adubação em mudas clonais de eucalipto. Foram usados os clones AEC 144, GG 100 e VM 01. O experimento foi instalado considerando um delineamento inteiramente casualizado, envolvendo diferentes frequências e lâminas de fertirrigação residual, bem como a utilização da adubação convencional utilizada pelo viveiro e um tratamento controle, sem uso de adubação. Para o clone AEC 14, os tratamentos com aplicações diárias de efluente, associados às lâminas de 2 e $3 \mathrm{~mm}$, proporcionaram, em geral, maior qualidade das mudas. Resultado parecido foi observado para o clone VM 01, em que o tratamento com aplicação diária e lâmina de $2 \mathrm{~mm}$ obteve resultados superiores. O clone GG 100 apresentou mudas de melhor qualidade com três aplicações semanais, independente da lâmina utilizada; com aplicação diária e lâmina de 3 mm; e com adubação convencional.
\end{abstract}

\section{Residual fertilization in clonal eucalyptus seedlings production}

\begin{abstract}
Despite the development over the years of technical and operational infrastructure for clonal nurseries, very few establishments'present waste and effluents reuse systems in productive process. The present study aimed at evaluating the use of clonal mini garden effluent in growth of eucalyptus clones seedlings. The clones AEC 144, GG 100 and VM 01were used. The experiment was carried out considering a totally randomized design, involving different frequencies and residual fertirrigation blade, as well as the use of conventional fertilization used by the nursery and a control, without fertilizers. AEC 14 clones treatments of daily effluent applications associated with 2- and 3-mm blades, resulted overall seedlings with higher quality. Similar results were observed with clone VM 01, wherein daily application and treatment with a $2 \mathrm{~mm}$ blade presented superior results. GG 100 clone presented seedlings with higher quality with applications three times a week independent of the fertirrigation blade; daily application and blade of $3 \mathrm{~mm}$; and conventional fertilization.
\end{abstract}

\section{Introdução}

A busca por destinações de resíduos e efluentes gerados pelas atividades produtivas representa, atualmente, um grande desafio para a sociedade, uma vez que se manejados de forma inadequada poderão gerar sérios impactos ao meio ambiente.
O uso de efluentes na agricultura tem sido praticado há muito tempo em várias partes do mundo (Ramos, 2007). A opção pela utilização de efluentes geralmente está associada à escassez de fontes hídricas de qualidade, o que tem levado países e centros de pesquisa a repensarem o emprego de águas de qualidade inferior na agricultura. Além disso, a utilização de efluentes contribui para a 
redução das concentrações de fertilizantes minerais utilizados para suprir as necessidades das culturas (Barros et al., 2012; Ribeiro et al., 2013; Monteiro et al., 2014; Mendes et al., 2016).

No segmento de produção de mudas, os viveiros clonais do gênero Eucalyptus destacam-se pelo número de estabelecimentos e quantidade de mudas produzidas (Freitas et al., 2013). O setor caracteriza-se como grande consumidor de água e fertilizantes, o que torna a utilização adequada desses insumos um fator de elevada importância (Freitag, 2007).

Apesar do desenvolvimento da estrutura técnica e operacional dos viveiros clonais do gênero Eucalyptus ao longo dos anos, poucos estabelecimentos apresentam sistemas de reaproveitamento de resíduos e efluentes do processo produtivo. Isso se torna um problema eminente, considerando que a atividade produz quantidades consideráveis de efluentes.

Um dos processos produtivos que apresenta elevada geração de efluentes em um viveiro de mudas é o minijardim clonal semi-hidropônico. Trata-se do ambiente onde estão localizadas as matrizes clonais que darão origem aos propágulos para formação das mudas. A elevada produtividade do minijardim clonal está diretamente associada ao manejo nutricional adequado (Brondani et al., 2012; Souza et al., 2015; Lopes et al., 2016).

O processo de nutrição adotado em minijardins clonais é composto por macro e micronutrientes, que variam de acordo com o material genético (clone), com o ambiente e com o sistema de condução adotado para as minicepas (Cunha et al., 2008). Normalmente, o manejo nutricional é realizado por meio de fertirrigações via gotejamento, em sistemas automatizados (Higashi et al., 2002).

Em estudo desenvolvido por Rodrigues (2007), avaliando o uso da água em unidades de produção de mudas, constatou-se que dos $200 \mathrm{~L}$ de solução de fertirrigação aplicados diariamente nos canaletões do minijardim clonal semi-hidropônico, aproximadamente $40 \%$ são drenadas, representando uma elevada perda de nutrientes por lixiviação e perdas financeiras para o viveiro.

Neste contexto, o desenvolvimento de estudos visando o reaproveitamento de resíduos e efluentes oriundos do processo produtivo de mudas pode contribuir significativamente para a otimização dos viveiros, gerando ganhos financeiros decorrentes da economia de insumos, bem como minimizando os impactos ambientais oriundos dos descartes dos efluentes gerados.

O objetivo dessa pesquisa foi avaliar o uso de efluente oriundo do minijardim clonal como adubação em mudas clonais de eucalipto.

\section{Material e métodos}

A pesquisa foi desenvolvida no viveiro clonal da empresa Via Verde Florestal, localizado no Município de Abadiânia, GO (16 $16^{\circ}$ '31'S e 4844'26”W). O clima da região, segundo Koppen \& Geiger (1928), é classificado como Aw, caracterizado por duas estações distintas, uma com período seco, entre os meses de maio a outubro, e outra com período chuvoso, entre os meses de novembro a abril.

Para caracterização química do efluente do minijardim clonal, realizaram-se três coletas intercaladas por um período de um mês durante o período de condução do experimento, onde foram coletados 1,5 $\mathrm{L}$ do efluente em cada amostragem, sendo determinado em laboratório o $\mathrm{pH}$, a condutividade elétrica e os teores de macro (nitrogênio, fósforo, potássio, magnésio, cálcio e enxofre) e micronutrientes (boro, manganês, molibdênio, ferro, zinco, cobre, além do elemento benéfico cobalto). Os resultados encontra-se expostos na (Tabela 1).

Tabela 1. Caracterização química do efluente do minijardim clonal utilizado para a adubação das mudas.

\begin{tabular}{lcc}
\hline \multicolumn{1}{c}{ Parâmetros } & Faixa de variação & Valores médios \\
\hline Nitrogênio $\left(\mathrm{g} \mathrm{kg}^{-1}\right)$ & $0,09-0,16$ & 0,12 \\
Fósforo $\left(\mathrm{g} \mathrm{kg}^{-1}\right)$ & $0,06-0,10$ & 0,07 \\
Potássio $\left(\mathrm{g} \mathrm{kg}^{-1}\right)$ & $0,23-0,45$ & 0,35 \\
Cálcio $\left(\mathrm{g} \mathrm{kg}^{-1}\right)$ & $0,24-0,49$ & 0,33 \\
Magnésio $\left(\mathrm{g} \mathrm{kg}^{1}\right)$ & $0,05-0,08$ & 0,06 \\
Enxofre $\left(\mathrm{g} \mathrm{kg}^{-1}\right)$ & $0,03-0,07$ & 0,05 \\
Cobre $\left(\mathrm{mg} \mathrm{kg}^{-1}\right)$ & $0,33-0,65$ & 0,50 \\
Ferro $\left(\mathrm{mg} \mathrm{kg}^{-1}\right)$ & $3,76-4,98$ & 4,40 \\
Manganês $\left(\mathrm{mg} \mathrm{kg}^{-1}\right)$ & $2,01-2,74$ & 2,45 \\
Zinco $\left(\mathrm{mg} \mathrm{kg}^{-1}\right)$ & $0,94-1,17$ & 1,10 \\
Cobalto $\left(\mathrm{mg} \mathrm{kg}^{-1}\right)$ & $0,01-0,02$ & 0,01 \\
Molibdênio $\left(\mathrm{mg} \mathrm{kg}^{-1}\right)$ & $0,01-0,03$ & 0,02 \\
Boro $\left(\mathrm{mg} \mathrm{kg}^{-1}\right)$ & $0,08-0,23$ & 0,12 \\
Condutividade elétrica $(\mathrm{dS} \mathrm{m}$ & \\
pH & $1,87-2,19$ & 2,05 \\
\hline
\end{tabular}

A adubação de cobertura utilizada pelo viveiro é realizada uma vez por semana, durante o período de permanência das mudas a pleno sol. A solução utilizada é composta por 4,6 kg de fosfato monoamônico (MAP), 
1,5 $\mathrm{kg}$ de cloreto de potássio, $90 \mathrm{~g}$ de sulfato de magnésio, $80 \mathrm{~g}$ de ácido bórico, $2 \mathrm{~kg}$ de sulfato de amônio, $30 \mathrm{~g}$ de sulfato de cobre, $60 \mathrm{~g}$ de sulfato de zinco, $20 \mathrm{~g}$ de ferrilene, $6 \mathrm{~kg}$ de super simples, $50 \mathrm{~g}$ de sulfato de manganês e $10 \mathrm{~g}$ de molibdato de sódio. A diluição é feita em um tanque de armazenamento, utilizando $1.000 \mathrm{~L} \mathrm{de}$ água. São aplicados $10 \mathrm{~L}$ da solução a cada 1.536 mudas. As concentrações dos nutrientes na solução podem ser observadas na (Tabela 2).

Tabela 2. Características químicas da adubação de cobertura utilizada pelo viveiro em estudo.

\begin{tabular}{cc}
\hline Nutrientes & Valores médios \\
\hline Nitrogênio $\left(\mathrm{g} \mathrm{kg}^{-1}\right)$ & 0,64 \\
Fósforo $\left(\mathrm{g} \mathrm{kg}^{-1}\right)$ & 0,60 \\
Potássio $\left(\mathrm{g} \mathrm{kg}^{-1}\right)$ & 5,50 \\
Cálcio $\left(\mathrm{g} \mathrm{kg}^{-1}\right)$ & 0,60 \\
Magnésio $\left(\mathrm{g} \mathrm{kg}^{-1}\right)$ & 0,20 \\
Enxofre $\left(\mathrm{g} \mathrm{kg}^{-1}\right)$ & 0,80 \\
Cobre $\left(\mathrm{mg} \mathrm{kg}^{-1}\right)$ & 5,00 \\
Ferro $\left(\mathrm{mg} \mathrm{kg}^{-1}\right)$ & 340,00 \\
Manganês $\left(\mathrm{mg} \mathrm{kg}^{-1}\right)$ & 85,00 \\
Zinco $\left(\mathrm{mg} \mathrm{kg}^{-1}\right)$ & 0,10 \\
Cobalto $\left(\mathrm{mg} \mathrm{kg}^{-1}\right)$ & 0,10 \\
Molibdênio $\left(\mathrm{mg} \mathrm{kg}^{-1}\right)$ & 0,80 \\
\hline
\end{tabular}

Foram utilizados os clones AEC 144 (Eucalyptus urophylla S. T. Blake registro $\mathrm{n}^{\circ}$ 21874), GG 100 (E. urophylla S. T. Blake registro $\mathrm{n}^{\circ}$ 21277) e VM 01 (E. camaldulensis Dehnh. x E. urophylla S. T. Blake registro $\mathrm{n}^{\mathrm{o}}$ 20766). Esses foram selecionados por serem os principais clones comercializados no viveiro da empresa e serem amplamente utilizados nos projetos de silvicultura em diversas regiões do país.

Para a produção das mudas, foram coletadas miniestacas no minijardim clonal dos três clones, com comprimento variando de 4 a $7 \mathrm{~cm}$, dois pares de folhas, em média, e dominância apical. O estaqueamento foi realizado em substrato composto por vermiculita, casca de arroz carbonizada e fibra de coco, em tubetes plásticos de $55 \mathrm{~cm}^{3}$. As mudas foram encaminhadas para a casa de vegetação, onde permaneceram por 28 dias, com temperatura em torno de $28{ }^{\circ} \mathrm{C}$, e umidade relativa do ar acima de $80 \%$, para favorecer o enraizamento. Após essa fase, as mudas foram transferidas para casa de sombra, com iluminação natural reduzida em 50\% para aclimatação, onde permaneceram por um período de 4 dias. Posteriormente, as mudas foram alocadas em bancadas de tela, onde permaneceram a pleno sol por um período de 88 dias até a avaliação final do experimento (120 dias de idade).

O experimento foi instalado considerando um delineamento inteiramente casualizado, com 11 tratamentos, envolvendo diferentes frequências de aplicações (número de aplicações), e diferentes lâminas de fertirrigação residual (quantidade do efluente utilizado), bem como a utilização da adubação convencional praticada pelo viveiro e um tratamento controle, sem uso de adubação (Tabela 3). Para avaliação das características morfológicas, foram consideradas 5 repetições de 10 mudas para cada tratamento. Os clones foram avaliados separadamente.

Tabela 3. Tratamentos utilizados no experimento.

\begin{tabular}{cc}
\hline Tratamentos & Descrição \\
\hline T1 & Aplicação diária do efluente + lâmina de $1 \mathrm{~mm}$ \\
T2 & Aplicação diária do efluente + lâmina de $2 \mathrm{~mm}$ \\
T3 & Aplicação diária do efluente + lâmina de $3 \mathrm{~mm}$ \\
T4 & Aplicação 2x na semana + lâmina de $1 \mathrm{~mm}$ \\
T5 & Aplicação 2x na semana + lâmina de $2 \mathrm{~mm}$ \\
T6 & Aplicação 2x na semana + lâmina de $3 \mathrm{~mm}$ \\
T7 & Aplicação 3x na semana + lâmina de $1 \mathrm{~mm}$ \\
T8 & Aplicação 3x na semana + lâmina de $2 \mathrm{~mm}$ \\
T9 & Aplicação 3x na semana + lâmina de $3 \mathrm{~mm}$ \\
T10 & Adubação convencional praticada pelo viveiro \\
T11 & Controle (sem adubação) \\
\hline
\end{tabular}

Após a transferência das mudas para o pátio a pleno sol, iniciou-se a aplicação dos tratamentos, utilizando o efluente do minijardim clonal e a adubação praticada pelo viveiro.

A coleta dos resíduos foi realizada diariamente. Foi utilizado recipiente com graduação volumétrica para aferição da quantidade a ser utilizada. A aplicação dos resíduos foi feita manualmente com uso de regador, distribuindo-se sobre as plantas de forma homogênea.

Os tratamentos foram dispostos em parcelas de $1 \mathrm{~m}^{2}$. Dessa forma, a aplicação das lâminas de 1, 2 e $3 \mathrm{~mm}$, consistiu na utilização de 1, 2 e 3 L por parcela, respectivamente. As aplicações foram realizadas sempre após a última irrigação ao final do dia. A lâmina de irrigação utilizada pelo viveiro e fixada para todos os tratamentos foi de $9 \mathrm{~mm}$ por dia, subdividida em três aplicações por aspersão.

Como a adubação convencional praticada pelo viveiro possui recomendação de aplicação de $10 \mathrm{~L}$ da solução para 
cada 1.536 mudas, e cada parcela apresenta capacidade para 300 mudas, proporcionalmente foram aplicados 1,9 L da solução por parcela, aplicado manualmente sobre as plantas. $\mathrm{O}$ tratamento sem adubação recebeu somente a irrigação utilizada pelo viveiro.

A altura da parte aérea $(\mathrm{H})$ e diâmetro do coleto (D) das plantas foram mensurados aos 60, 90 e 120 dias. As massas secas da parte aérea (MSPA), das raízes (MSR) e total (MST), foram avaliadas aos 120 dias. A partir desses resultados, foram calculadas as razões entre as variáveis altura da parte aérea e diâmetro do coleto (H/D) e entre massa seca da parte aérea e massa seca das raízes (MSPA/MSR), e o índice de qualidade de Dickson (IQD $=\mathrm{MST} /(\mathrm{H} / \mathrm{D}+\mathrm{MSA} / \mathrm{MSR})$ (Dickson et al., 1960).

Após a verificação da homogeneidade pelo teste de Bartlett e normalidade dos dados pelo teste de Shapiro Wilk, os dados foram submetidos à análise de variância (ANOVA) e, quando detectadas diferenças significativas, os resultados foram submetidos ao teste de Scott Knott para comparação de médias a $5 \%$ de probabilidade, utilizando o software $R$, pacote ExpDes (Ferreira et al., 2013).

\section{Resultados e discussão}

Os valores para a condutividade elétrica da água (CE), $\mathrm{pH}$, macro e micronutrientes do efluente do minijardim clonal, estão apresentados na (Tabela 4). Para efeito de comparação, também constam os valores de referência para adubação diária do gênero Eucalyptus na fase de rustificação (Higashi et al., 2002).

Para a utilização de efluentes para fertirrigação, a salinidade é um dos principais fatores a ser analisado para o monitoramento do reuso da água. Os valores da CE do efluente do minijardim clonal apresentou média de 2,05 dS m${ }^{-1}$. Em estudos desenvolvidos por Batista et al. (2013), com resíduos da suinocultura na produção de E. urophylla, o valor da CE do efluente apresentou média de $2,72 \mathrm{dS} \mathrm{m}^{-1}$, resultado próximo do encontrado por Rezende (2003), analisando o uso de efluente tratado de fábrica de celulose Kraft branqueada na produção de mudas do mesmo gênero, em que a condutividade variou de 2,7 a 4,3 $\mathrm{dS} \mathrm{m}^{-1}$. Em nenhum dos estudos constataram-se sintomas de toxidez nas mudas devido ao excesso de sais no efluente.

Os valores de pH da solução oscilaram entre 5,6 e 6,7 ao longo do período de monitoramento. Tais resultados encontram-se um pouco abaixo da faixa considerada adequada por Ayers et al. (1999), que estabelecem valores de $\mathrm{pH}$ ideais, baseados em critérios de salinidade e toxicidade para fertirrigação, variando entre 6,5 a 8,4.

Tabela 4. Caracterização química do efluente do minijardim clonal utilizado na adubação das mudas e recomendação de adubação diária na fase de rustificação para Eucalyptus spp.

\begin{tabular}{lccc}
\hline \multicolumn{1}{c}{ Nutrientes } & $\begin{array}{c}\text { Faixa de } \\
\text { variação }\end{array}$ & $\begin{array}{c}\text { Valores } \\
\text { médios }\end{array}$ & $\begin{array}{c}\text { Recomendação } \\
\text { de adubação } \\
\text { diária* }\end{array}$ \\
\hline Nitrogênio $\left(\mathrm{g} \mathrm{kg}^{-1}\right)$ & $0,09-0,16$ & 0,12 & $0-0,05$ \\
Fósforo $\left(\mathrm{g} \mathrm{kg}^{-1}\right)$ & $0,06-0,10$ & 0,07 & $0,05-0,10$ \\
Potássio $\left(\mathrm{g} \mathrm{kg}^{-1}\right)$ & $0,23-0,45$ & 0,35 & $0,15-0,30$ \\
Cálcio $\left(\mathrm{g} \mathrm{kg}^{-1}\right)$ & $0,24-0,49$ & 0,33 & $0,15-0,30$ \\
Magnésio $\left(\mathrm{g} \mathrm{kg}^{-1}\right)$ & $0,05-0,08$ & 0,06 & $0,04-0,06$ \\
Enxofre $\left(\mathrm{g} \mathrm{kg}^{-1}\right)$ & $0,03-0,07$ & 0,05 & $0,05-0,08$ \\
Cobre $\left(\mathrm{mg} \mathrm{kg}^{-1}\right)$ & $0,33-0,65$ & 0,50 & $0,03-0,06$ \\
Ferro $\left(\mathrm{mg} \mathrm{kg}^{-1}\right)$ & $3,76-4,98$ & 4,40 & $3-7$ \\
Manganês $\left(\mathrm{mg} \mathrm{kg}^{-1}\right)$ & $2,01-2,74$ & 2,45 & $0,3-0,8$ \\
Zinco $\left(\mathrm{mg} \mathrm{kg}^{-1}\right)$ & $0,94-1,17$ & 1,10 & $0,05-0,10$ \\
Cobalto $\left(\mathrm{mg} \mathrm{kg}^{-1}\right)$ & $0,01-0,02$ & 0,01 & Não avaliado \\
Molibdênio $\left(\mathrm{mg} \mathrm{kg}^{-1}\right)$ & $0,01-0,03$ & 0,02 & $0,01-0,02$ \\
Boro $\left(\mathrm{mg} \mathrm{kg}^{-1}\right)$ & $0,08-0,23$ & 0,12 & $0,3-0,6$ \\
Condutividade & $1,87-2,19$ & 2,05 & Não avaliado \\
elétrica $\left(\mathrm{dS} \mathrm{m}^{-1}\right)$ & $5,6-6,7$ & 5,95 & Não avaliado \\
pH & & & \\
\hline * Fonte: Higashi et al $(2002)$ & &
\end{tabular}

Os nutrientes fósforo, magnésio, enxofre, molibdênio e ferro presentes no efluente estavam dentro da faixa recomendada por Higashi et al. (2002), para adubação de rustificação em mudas do gênero Eucalyptus. No entanto, nitrogênio e potássio apresentaram valores acima dos recomendados pelos autores e cobre e manganês apresentaram as maiores discrepâncias em relação aos valores de referência.

Com relação aos macronutrientes, observa-se que o potássio apresentou as maiores concentrações, seguido do cálcio e nitrogênio. A relação potássio-nitrogênio $(\mathrm{K} / \mathrm{N})$ do efluente analisado ficou na faixa de 2,91 , sendo esse valor próximo da faixa considerada adequada. Segundo Higashi et al. (2002), para adubação diária na fase de rustificação, recomenda-se que a quantidade de potássio aplicada seja superior a de nitrogênio, em uma relação próxima de $3 / 1$, favorecendo, com isso, o engrossamento do caule e aumentando a resistência da muda ao estresse do plantio, sendo o potássio elemento mais demandado na fase de rustificação.

Foram observadas diferenças significativas para altura e diâmetro do coleto em todos os clones avaliados (Tabela 5). 
Tabela 5. Resumo da análise de variância para a altura e diâmetro do coleto $(\mathrm{cm})$ aos 60,90 e 120 dias de idade.

\begin{tabular}{|c|c|c|c|c|c|c|c|c|}
\hline \multicolumn{9}{|c|}{ Valores de quadrados médios } \\
\hline \multirow{4}{*}{ AEC 144} & $\mathrm{FV}$ & GL & $\mathrm{H} 60$ & $\mathrm{H} 90$ & H120 & D60 & D90 & D120 \\
\hline & Tratamento & 10 & $8,96 * *$ & $12,64 * *$ & $13,88^{* *}$ & $0,81 * *$ & $0,25 * *$ & $0,33 * *$ \\
\hline & Média geral & & 19,60 & 26,18 & 29,32 & 2,21 & 2,78 & 3,17 \\
\hline & $\mathrm{CV} \%$ & & 4,08 & 4,36 & 5,04 & 5,51 & 4,80 & 6,25 \\
\hline \multirow{3}{*}{ GG100 } & Tratamento & 10 & $7,42 * *$ & $23,3^{* *}$ & $37,77 * *$ & $5,01 * *$ & $5,45^{* *}$ & $9,51 * *$ \\
\hline & Média geral & & 18,44 & 26,05 & 29,68 & 2,12 & 2,73 & 3,19 \\
\hline & $\mathrm{CV} \%$ & & 5,09 & 4,76 & 5,84 & 4,86 & 5,92 & 5,12 \\
\hline \multirow{3}{*}{ VM 01} & Tratamento & 10 & $3,32 * *$ & $19,98 * *$ & $25,26^{* *}$ & $2,68^{*}$ & $5,03 * *$ & $6,23^{* *}$ \\
\hline & Média geral & & 19,09 & 26,72 & 30,38 & 2,30 & 2,85 & 3,32 \\
\hline & $\mathrm{CV} \%$ & & 5,07 & 4,27 & 5,09 & 5,67 & 6,17 & 6,17 \\
\hline
\end{tabular}

$\mathrm{Na}$ avaliação de crescimento em altura, as mudas clonais apresentaram diferenças significativas entre todos os tratamentos avaliados. Na primeira avaliação realizada aos 60 dias, o tratamento com adubação convencional (T10), sem adubação (T11), e os tratamentos T1 e T2 apresentaram valores médios inferiores para o clone AEC 144. Para os clones GG 100 e VM 01, os tratamentos com adubação, convencional e sem adubação, apresentaram médias semelhantes aos tratamentos utilizando adubação residual (Figura 1).

A partir dos 90 dias (Figura 1), os tratamentos utilizando as maiores frequências e lâminas do efluente e o tratamento com adubação convencional começaram a proporcionar maior crescimento para os clones AEC 144 e VM 01. Para o clone AEC 144 os tratamentos, T2, T3, T6, T7, T8, T9 e T10, apresentaram médias superiores sem diferirem entre si, resultado semelhante ao observado para o clone VM 01 em que os tratamentos T2, T3, T8, T9 e T10 obtiveram os maiores valores, enquanto para o clone GG 100 apenas os tratamentos T3 e T9 apresentaram as maiores médias.

Para os clones AEC 144 e VM 01, os tratamentos que utilizaram a frequência de duas aplicações semanais independente da lâmina, apresentaram valores estatisticamente iguais ao tratamento com adubação convencional. Para todos os clones, o tratamento sem adubação (T11), proporcionou as menores médias para altura de plantas (Figura 1).
A altura é uma importante variável utilizada na classificação e seleção de mudas, representando um importante papel na sobrevivência e desenvolvimento em campo (Reis et al., 2008). Os valores médios de altura para os três clones avaliados aos 120 dias variaram de 24,49 a $34,26 \mathrm{~cm}$. Embora existam controvérsias em relação ao tamanho ideal das mudas de eucalipto para o plantio, os resultados se enquadram no padrão estabelecido por Gomes et al. (2003), como referência de qualidade de mudas do gênero (entre 15 e $35 \mathrm{~cm}$ ).

Para o clone AEC 144, o tratamento que apresentou as maiores médias foi o T2 $(31,68 \mathrm{~cm})$, com altura 7,7\% maior que o tratamento T10, que usava apenas adubação convencional $(29,27 \mathrm{~cm})$, e $10,9 \%$ maior, quando comparado com o T11 (25,22 cm). Para o clone GG 100, o melhor tratamento foi o T3 $(34,26 \mathrm{~cm})$, que associava aplicação diária e lâmina de $3 \mathrm{~mm}$, apresentou diferença superior de $8,6 \%$ ao T10 $(31,31 \mathrm{~cm})$ e $25,5 \%$ ao T11 $(25,51 \mathrm{~cm})$, e o clone VM 01 que também apresentou o $\mathrm{T} 3(33,56 \mathrm{~cm})$ com a maior média, resultou em diferença $9,5 \%$ que o T10 $(30,36 \mathrm{~cm})$ e $27,0 \%$ que o T11 $(24,49$ $\mathrm{cm})$. Portanto, para a variável altura de mudas, o T3, que associava frequência diária de aplicação + lâmina de 3 $\mathrm{mm}$, foi o único que apresentou médias estatisticamente superiores para os três clones (Figura 1). Tal fato pode ser justificado pela maior disponibilidade hídrica e de nutrientes proporcionada por esse tratamento. 

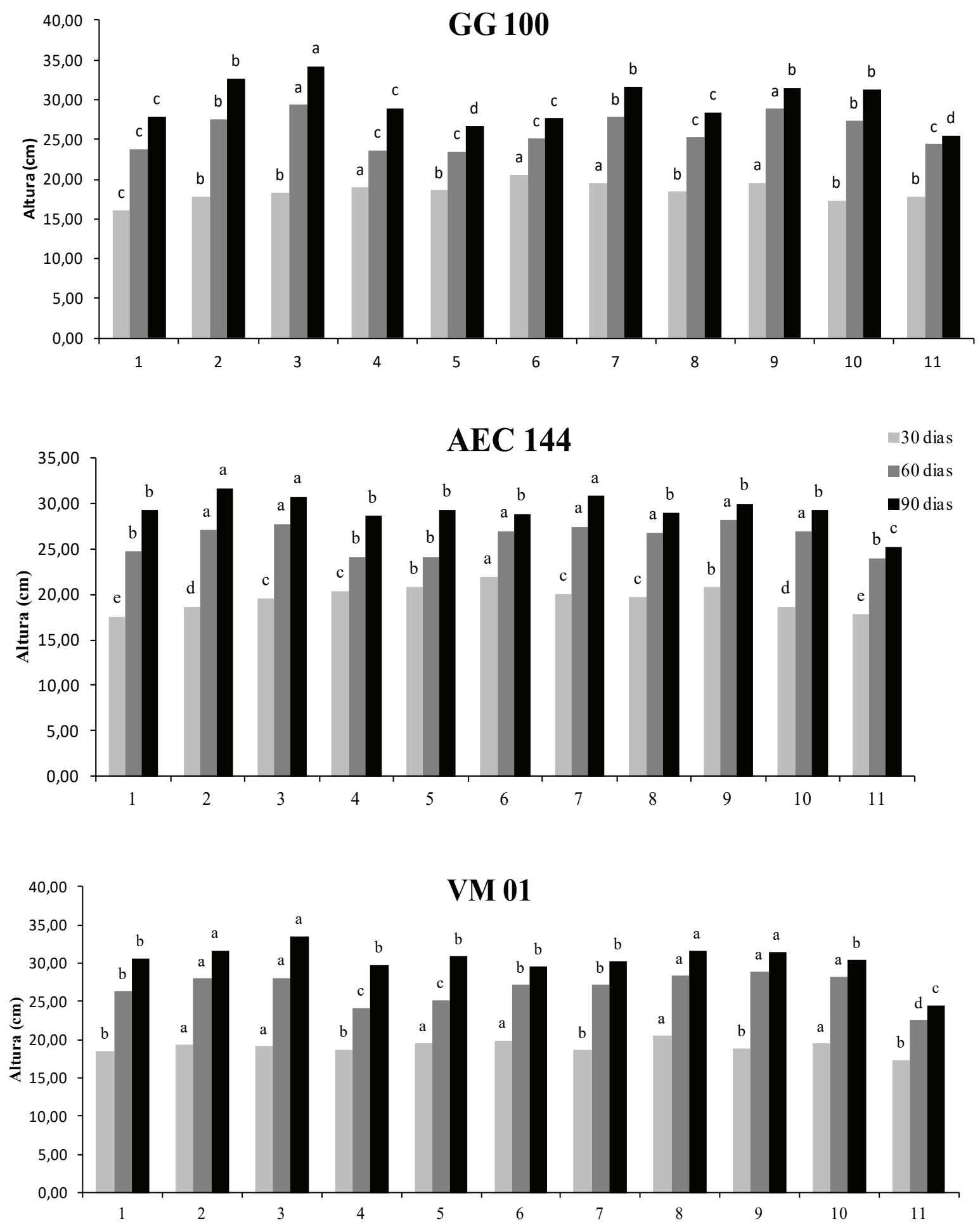

Figura 1. Valores médios da altura da parte aérea de mudas dos clones AEC 144, GG 100 e VM 01, em idades de 60, 90 e 120 dias. T1, T2 e T3 = aplicação diária + lâmina de $1 \mathrm{~mm}, 2 \mathrm{~mm}$ e $3 \mathrm{~mm}$, respectivamente; T4, T5 e T6 = aplicação 2 vezes na semana + lâmina de 1mm, $2 \mathrm{~mm}$ e $3 \mathrm{~mm}$, respectivamente; T7, T8 e T9 = aplicação 3 vezes na semana + lâmina de $1 \mathrm{~mm}, 2 \mathrm{~mm}$ e $3 \mathrm{~mm}$, respectivamente; T10 = adubação convencional praticada no viveiro; T11 $=$ sem adubação. Colunas da mesma cor seguidas pela mesma letra não diferem pelo teste de $\operatorname{Scott} \operatorname{Knott}(\alpha=0,05)$. 
As representações de médias do diâmetro do coleto podem ser observadas na Figura 2. Na primeira avaliação, aos 60 dias, os tratamentos $\mathrm{T} 3$ e $\mathrm{T} 4$ proporcionaram maiores diâmetros do coleto para o clone AEC 144. Para o clone GG 100 os tratamentos T4, T5, T7, T8 e
T10, apresentaram os maiores resultados de média, sem diferirem entre si, e para o clone VM 01, a maioria dos tratamentos não apresentou diferenças significativas entre si, apenas T1, T9 e T11 diferiram dos demais com médias significativamente inferiores.
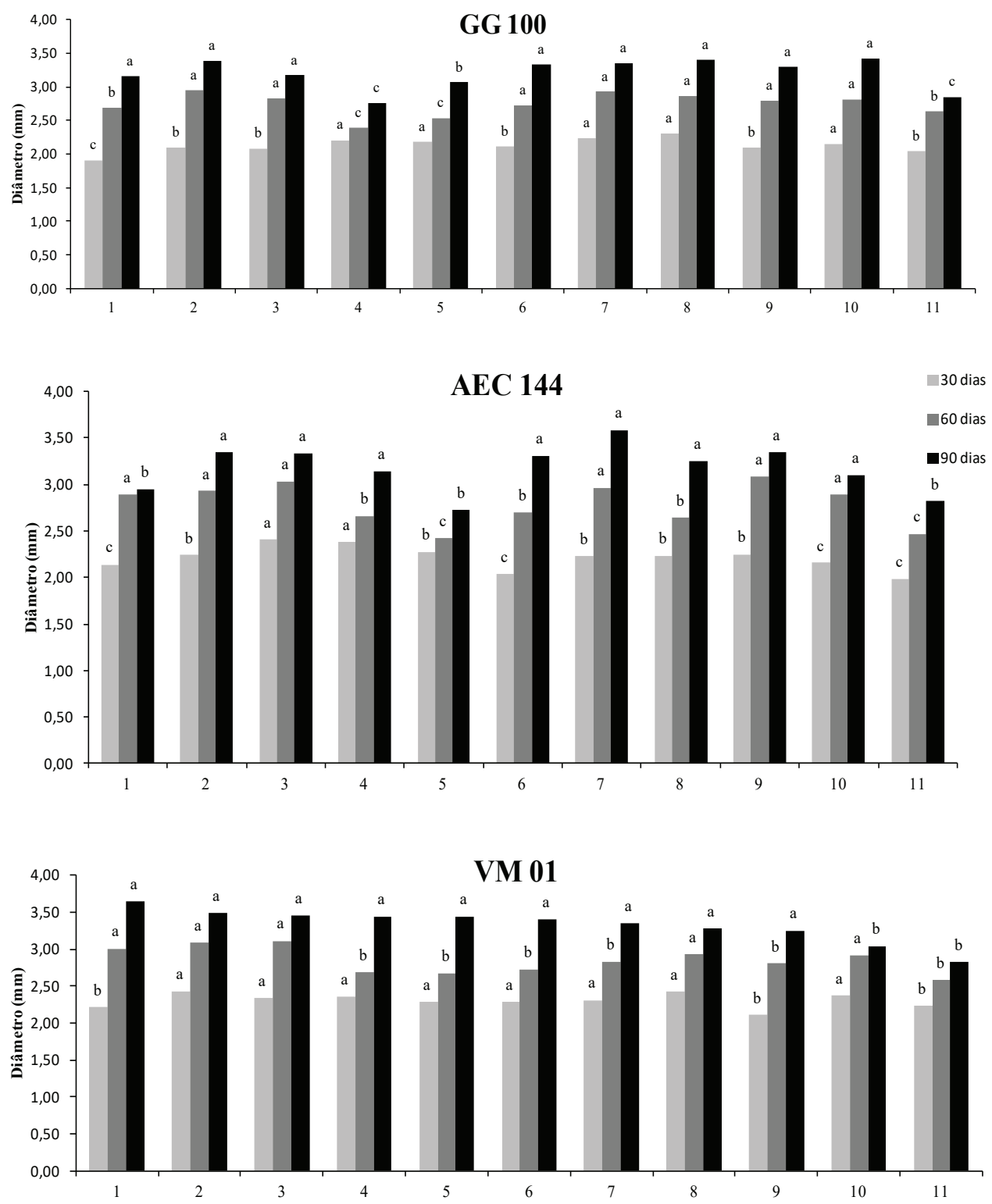

Figura 2. Valores médios do diâmetro do coleto de mudas dos clones AEC 144, GG 100 e VM 01, em idades de 60, 90 e 120 dias. T1, T2 e T3 = aplicação diária + lâmina de $1 \mathrm{~mm}, 2 \mathrm{~mm}$ e $3 \mathrm{~mm}$, respectivamente; T4, T5 e T6 = aplicação 2 vezes na semana + lâmina de 1mm, $2 \mathrm{~mm}$ e $3 \mathrm{~mm}$, respectivamente;; T7, T8 e T 9 = aplicação 3 vezes na semana + lâmina de $1 \mathrm{~mm}, 2 \mathrm{~mm}$ e $3 \mathrm{~mm}$, respectivamente; $\mathrm{T} 10=$ adubação convencional praticada no viveiro; $\mathrm{T} 11=$ sem adubação. Colunas da mesma cor seguidas pela mesma letra não diferem pelo teste de $\operatorname{Scott} \operatorname{Knott}(\alpha=0,05)$. 
Na segunda avaliação aos 90 dias, notou-se que para os três clones os tratamentos com maiores frequências de aplicação (diariamente e três aplicações por semana), independente da lâmina utilizada, e o tratamento com adubação convencional, em geral, mostraramse superiores, quando comparado aos tratamentos utilizando duas aplicações semanais e com o tratamento controle, sem adubação.

No entanto, a maioria dos tratamentos para os três clones testados não apresentaram diferenças significativas entre si aos 120 dias. Para o clone AEC 144, apenas os tratamentos T1, T5 e T11 diferiram dos demais, com médias significativamente inferiores. Para o clone GG 100 foram os tratamentos T4, T5 e T11 que apresentaram médias inferiores, quando comparado aos outros tratamentos, e para o clone VM 01, apenas o tratamento controle (T11) diferiu dos demais, apresentando média estatisticamente menor. Resultado semelhante foi obtido por Costa et al. (2012), em estudo analisando a produção de mudas de
Enterolobium timbouva Mart. (timbaúba), sob diferentes concentrações de efluente doméstico tratado. Esses autores não encontraram diferenças significativas entre os tratamentos em relação ao diâmetro do coleto.

O diâmetro do coleto é uma das características que melhor prediz o desempenho das mudas no pós-plantio. Valores superiores deste caractere geralmente estão relacionados a um sistema radicular abundante, o que favorece o estabelecimento e o crescimento das plantas em condições de mato-competição (Davide \& Faria, 2008; Ritchie et al., 2010; Cargnelutti Filho et al., 2012). Todos os tratamentos estudados apresentaram valores de diâmetro do coleto adequados ou muito próximo do proposto por Sturion \& Antunes (2000), para que as mudas sejam consideras aptas para o plantio, que é de 2 a $3,5 \mathrm{~cm}$.

Houve diferenças significativas para a massa seca da parte aérea, massa seca de raízes (Tabela 6), relação massa seca da parte aérea $\mathrm{x}$ massa seca de raízes e relação altura $\mathrm{x}$ diâmetro para todos os clones avaliados (Tabela 7).

Tabela 6. Valores médios para massa seca da parte aérea (MSPA), massa seca de raízes (MSR) e massa seca total (MST), dos três clones avaliados aos 120 dias após o início dos tratamentos.

\begin{tabular}{cccccccccc}
\hline \multicolumn{4}{c}{ Clone AEC 144 } & \multicolumn{3}{c}{ Clone GG 100 } \\
\hline Trat & MSPA & MSR & MST & MSPA & MSR & MST & MSPA & MSR & MST \\
& & & & \multicolumn{2}{c}{ Clone VM 01 } \\
\hline 1 & $2,28 \mathrm{a}^{*}$ & $1,06^{\text {ns }}$ & $3,34 \mathrm{a}^{*}$ & $1,82 \mathrm{a}^{* *}$ & $0,81^{\text {ns }}$ & $2,63^{\text {ns }}$ & $2,52 \mathrm{a}^{* *}$ & $0,81^{\text {ns }}$ & $3,32^{\text {ns }}$ \\
2 & $2,23 \mathrm{a}$ & 0,98 & $3,21 \mathrm{a}$ & $1,97 \mathrm{a}$ & 0,84 & 2,71 & $2,58 \mathrm{a}$ & 0,84 & 3,42 \\
3 & $2,22 \mathrm{a}$ & 1,06 & $3,28 \mathrm{a}$ & $1,70 \mathrm{a}$ & 0,84 & 2,54 & $2,57 \mathrm{a}$ & 0,84 & 3,41 \\
4 & $1,96 \mathrm{~b}$ & 0,94 & $2,90 \mathrm{a}$ & $1,63 \mathrm{a}$ & 0,80 & 2,43 & $2,12 \mathrm{~b}$ & 0,80 & 2,92 \\
5 & $1,76 \mathrm{~b}$ & 0,83 & $2,59 \mathrm{~b}$ & $1,79 \mathrm{a}$ & 0,82 & 2,61 & $2,23 \mathrm{~b}$ & 0,82 & 3,06 \\
6 & $1,70 \mathrm{~b}$ & 0,86 & $2,56 \mathrm{~b}$ & $2,00 \mathrm{a}$ & 0,72 & 2,73 & $2,08 \mathrm{~b}$ & 0,72 & 2,80 \\
7 & $2,10 \mathrm{a}$ & 0,94 & $3,04 \mathrm{a}$ & $2,00 \mathrm{a}$ & 0,83 & 2,83 & $2,47 \mathrm{a}$ & 0,83 & 3,20 \\
8 & $1,80 \mathrm{~b}$ & 0,86 & $2,74 \mathrm{~b}$ & $1,89 \mathrm{a}$ & 0,87 & 2,76 & $2,41 \mathrm{a}$ & 0,87 & 3,28 \\
9 & $1,93 \mathrm{~b}$ & 0,99 & $2,91 \mathrm{a}$ & $1,74 \mathrm{a}$ & 0,87 & 2,61 & $2,41 \mathrm{a}$ & 0,87 & 3,28 \\
10 & $2,00 \mathrm{~b}$ & 0,98 & $3,98 \mathrm{a}$ & $1,72 \mathrm{a}$ & 0,80 & 2,52 & $2,44 \mathrm{a}$ & 0,80 & 3,24 \\
11 & $1,80 \mathrm{~b}$ & 0,74 & $2,55 \mathrm{~b}$ & $1,29 \mathrm{~b}$ & 0,99 & 2,28 & $1,82 \mathrm{~b}$ & 0,92 & 2,73 \\
\hline
\end{tabular}

ns $=$ não significativo; $*$ e ** = significativo a $5 \%$ e $1 \%$, respectivamente; Trat $=$ tratamentos; T1, T2 e T3 = aplicação diária + lâmina de $1 \mathrm{~mm}, 2 \mathrm{~mm}$ e $3 \mathrm{~mm}$, respectivamente; T4, T5 e T6 = aplicação 2 vezes na semana + lâmina de $1 \mathrm{~mm}, 2 \mathrm{~mm}$ e $3 \mathrm{~mm}$, respectivamente;; T7, T8 e T 9 = aplicação 3 vezes na semana + lâmina de $1 \mathrm{~mm}, 2 \mathrm{~mm}$ e $3 \mathrm{~mm}$, respectivamente; T10 = adubação convencional praticada no viveiro; T11 = sem adubação. Médias seguidas pela mesma letra na coluna não diferem entre si, pelo teste de Scott Knott $(\alpha=0,05)$. 
Tabela 7. Valores médios para relação altura x diâmetro do coleto (H/D), massa seca da parte aérea $\mathrm{x}$ massa seca de raízes (MSPA/MSR) e índice de qualidade de Dickson (IQD) das mudas clonais de eucalipto.

\begin{tabular}{|c|c|c|c|c|c|c|c|c|c|}
\hline \multirow[b]{2}{*}{ Trat } & \multicolumn{3}{|c|}{ Clone AEC 144} & \multicolumn{3}{|c|}{ Clone GG 100} & \multicolumn{3}{|c|}{ Clone VM 01} \\
\hline & H/D & MSPA/MSR & IQD & H/D & MSPA/MSR & IQD & H/D & MSPA/MSR & IQD \\
\hline 1 & $7,87 \mathrm{c}^{* *}$ & $2,10^{\mathrm{ns}}$ & $0,30^{\mathrm{ns}}$ & $8,80 b^{* *}$ & $2,26 a^{*}$ & $0,23^{\mathrm{ns}}$ & $8,97 b^{*}$ & $3,13 a^{*}$ & $0,27^{\text {ns }}$ \\
\hline 2 & $8,16 \mathrm{c}$ & 2,30 & 0,26 & $9,80 \mathrm{a}$ & $2,24 \mathrm{a}$ & 0,21 & $9,06 \mathrm{~b}$ & $3,06 \mathrm{a}$ & 0,28 \\
\hline 3 & $8,23 \mathrm{c}$ & 2,10 & 0,26 & $11,00 \mathrm{a}$ & $2,06 a$ & 0,20 & $9,74 \mathrm{a}$ & $3,07 \mathrm{a}$ & 0,27 \\
\hline 4 & $8,57 \mathrm{~b}$ & 2,10 & 0,23 & $9,20 \mathrm{~b}$ & $2,06 a$ & 0,19 & $8,40 \mathrm{~b}$ & $2,68 b$ & 0,23 \\
\hline 5 & $8,56 \mathrm{~b}$ & 2,10 & 0,24 & $10,60 \mathrm{a}$ & $2,18 \mathrm{a}$ & 0,25 & $9,84 \mathrm{a}$ & $2,72 b$ & 0,26 \\
\hline 6 & $9,05 \mathrm{~b}$ & 2,00 & 0,31 & $8,60 \mathrm{~b}$ & $2,79 \mathrm{a}$ & 0,24 & $9,55 \mathrm{a}$ & $2,87 \mathrm{~b}$ & 0,24 \\
\hline 7 & $10,48 \mathrm{a}$ & 2,30 & 0,33 & $8,30 \mathrm{~b}$ & $2,53 \mathrm{a}$ & 0,23 & $8,53 b$ & $2,86 \mathrm{~b}$ & 0,42 \\
\hline 8 & $9,10 \mathrm{~b}$ & 1,90 & 0,26 & $9,40 \mathrm{~b}$ & $2,32 \mathrm{a}$ & 0,26 & $9,31 \mathrm{a}$ & $2,84 \mathrm{~b}$ & 0,27 \\
\hline 9 & $8,80 \mathrm{~b}$ & 1,90 & 0,25 & $8,50 \mathrm{~b}$ & $2,06 \mathrm{a}$ & 0,23 & $9,31 \mathrm{a}$ & $2,84 \mathrm{~b}$ & 0,28 \\
\hline 10 & $9,10 \mathrm{~b}$ & 2,10 & 0,26 & $9,50 \mathrm{~b}$ & $2,16 \mathrm{a}$ & 0,22 & $9,44 \mathrm{a}$ & $3,08 \mathrm{a}$ & 0,29 \\
\hline 11 & $8,70 \mathrm{~b}$ & 2,50 & 0,22 & $9,00 \mathrm{~b}$ & $1,32 b$ & 0,22 & $8,68 b$ & $1,98 \mathrm{c}$ & 0,26 \\
\hline
\end{tabular}

ns = não significativo; $*$ e ** = significativo a $5 \%$ e $1 \%$ de probabilidade; Trat $=$ tratamentos; T1, T2 e T3 = aplicação diária + lâmina de 1 mm, $2 \mathrm{~mm}$ e $3 \mathrm{~mm}$, respectivamente; T4, T5 e T6 = aplicação 2 vezes na semana + lâmina de 1mm, $2 \mathrm{~mm}$ e $3 \mathrm{~mm}$, respectivamente;; T7, T8 e T $9=$ aplicação 3 vezes na semana + lâmina de $1 \mathrm{~mm}, 2 \mathrm{~mm}$ e $3 \mathrm{~mm}$, respectivamente; T10 = adubação convencional praticada no viveiro; T11 = sem adubação. Médias seguidas pela mesma letra na coluna não diferem entre si pelo teste de $\operatorname{Scott} \operatorname{Knott}(\alpha=0,05)$.

Para a massa seca da parte aérea do clone AEC 144, os tratamentos com aplicações diárias (T1, T2 e T3) e o tratamento com três aplicações semanais e lâmina de $1 \mathrm{~mm}$ (T7) apresentaram médias superiores, quando comparadas aos outros tratamentos, não diferindo entre si. Para o clone GG 100 apenas o tratamento controle, sem adubação, diferiu dos demais tratamentos, apresentando média significativamente inferior. Para o clone VM 01 os tratamentos com as maiores frequências de aplicações (diárias e três aplicações semanais) e o tratamento com adubação convencional apresentaram as maiores médias, não diferindo entre si.

A massa seca da parte aérea está relacionada com o desenvolvimento do caule e quantidade de folhas. Tal característica é muito importante, uma vez que as folhas são responsáveis pela realização da fotossíntese (Carmo, 2012).

Para a massa seca de raízes, nenhum dos clones avaliados apresentaram diferenças significativas. Tal fator pode estar relacionado à restrição do crescimento das raízes imposta pelo tubete aos 120 dias. Em pesquisa analisando o crescimento de mudas de Eucalyptus grandis em diferentes tamanhos de tubetes $(50,110$, 200 e $280 \mathrm{~cm}^{3}$ ) e fertilização com N-P-K, Gomes et al. (2003) constataram que a massa da matéria seca das raízes apresentou influência significativa, sendo as maiores médias encontradas nos tratamentos com tubetes de maior volume, independente da fertilização aplicada. De acordo com os autores, os tratamentos que utilizaram tubetes de menor volume apresentaram um menor índice de massa seca de raízes, devido às limitações físicas impostas pelo recipiente. Resultados parecidos foram observados por Santos et al. (2000) em mudas de Cryptomeria japonica, cuja maior massa seca das raízes foi relacionada com o maior volume do tubete.

Apenas o clone AEC 144 apresentou diferenças significativas de massa seca total (MST) entre os tratamentos, sendo que as maiores frequências de aplicação (diariamente e três vezes por semana) e a adubação convencional apresentaram as maiores médias (Tabela 6).

Foram observados comportamentos diferentes para os três clones na relação H/D. Para o AEC 144 os tratamentos com aplicações diárias expressaram as menores médias, sendo que o tratamento (T1) apresentou o menor valor absoluto. Os tratamentos utilizando três aplicações por semana apresentaram as menores médias para o clone GG 100, sendo T7 o que resultou em menor valor absoluto. Os menores valores do clone VM 01 foram obtidos com aplicações diárias e menores lâminas (T1 e T2) e os tratamentos T4, T7 e T11.

A relação H/D exprime o equilíbrio de crescimento de uma planta, devendo estar entre 5,4 e 8,1 (Carneiro, 1995). O índice também é denominado de quociente de 
robustez, pois fornece informações de quão delgada está a muda. Para Araújo et al. (2014), quanto menor for o valor deste índice, maior será a qualidade e capacidade das mudas sobreviverem e se estabelecerem em campo.

Em geral, as mudas de eucalipto apresentam maiores incrementos em altura do que em diâmetro de coleto. Os valores de $\mathrm{H} / \mathrm{D}$, considerando todos os tratamentos, variaram de 7,87 a 10,48 para o clone AEC 144, de 8,30 a 11,00 para o clone GG 100 e de 8,40 a 9,74 para o clone VM 01. Apesar de não estarem na faixa recomendada por Carneiro (1995), quando comparado a estudos utilizando outros tipos de efluentes o resultado do índice mostrouse menor. Valores acima do recomendado para relação H/D, foram encontrados por Palissari et al. (2009), em estudo utilizando resíduos da suinocultura na produção de mudas de Eucalyptus grandis, no qual a relação $\mathrm{H} / \mathrm{D}$, variou de 10,74 a 12,81 . Resultados parecidos foram encontrados por Lougon (2010), analisando o crescimento de mudas de eucalipto irrigadas com água de diferentes qualidade observou índices oscilando entre 11,19 a 14,03, sendo que o tratamento que resultou em menores médias foi com efluente doméstico tratado.

Para a relação massa seca da parte aérea / massa seca de raízes (MSPA/MSR), o clone AEC 144 não apresentou respostas significativas em relação aos tratamentos. Apenas o tratamento sem adubação do clone GG 100 diferiu significativamente dos demais, apresentando média inferior aos outros tratamentos. Para o clone VM 01 os tratamentos com aplicações diárias (T1, T2 e T3) e o tratamento utilizando adubação convencional obtiveram as maiores médias sem diferirem entre si. $\mathrm{O}$ presente resultado pode estar relacionado à maior disponibilidade de nutrientes que os tratamentos com aplicações diárias proporcionaram (Tabela 7).

Para o índice de qualidade de Dickson (IQD) não foram encontradas diferenças significativas entre os tratamentos em nenhum dos clones avaliados (Tabela 7). Segundo Gomes (2001), mudas de boa qualidade apresentam valores de IQD superiores a 0,20. Apesar de não ter ocorrido diferenças nos clones avaliados, nota-se que os valores médios de todos os tratamentos ficaram acima do limite definido para o índice, indicando boa qualidade das mudas produzidas.

\section{Conclusão}

Os tratamentos utilizando as maiores frequências de aplicação do efluente apresentaram resultados superiores para os três clones. Para o clones AEC 144 os tratamentos com aplicações diárias do efluente, associados às lâminas de 2 e $3 \mathrm{~mm}$, proporcionaram, em geral, maior qualidade das mudas. Resultado parecido foi observado para o clone VM 01 com aplicação diária e lâmina de 2 mm. Para o clone GG 100 os tratamentos com três aplicações semanais independente da lâmina utilizada, o tratamento com aplicação diária e lâmina de $3 \mathrm{~mm}$ e a adubação convencional produziram mudas de melhor qualidade.

A utilização do efluente do minijardim clonal na adubação de mudas de eucalipto apresentou resultados promissores, pois além de propiciar mudas com maior padrão de qualidade, permite o reaproveitamento do efluente gerado no minijardim clonal.

\section{Referências}

Araújo, et al. Qualidade das mudas de espécies arbóreas de mangue cultivadas em viveiro e diferentes substratos. Acta Ambiental Catarinense, v. 11, n. 1, p. 21-32, 2014. DOI:10.24021/raac. v11i1/2.1798.

Ayers, R. S. et al.Qualidade da água para agricultura. 2. ed. Campina Grande: UFPB, 1999. 153 p.

Barros, K. K. et al. Nematode suppression and growth stimulation in corn plants (Zea mays L.) irrigated with domestic effluent. WaterScience and Technology, v. 66, n. 3, p. 681-688, 2012.

Batista, R. O. et al. Efeito da água residuária da suinocultura no desenvolvimento e qualidade de mudas de Eucalyptus urophylla produzidas em substrato de resíduos sólidos urbanos. Ambi-Água, v. 8, n. 2, p. 180-191, 2013. DOI:10.4136/1980-993X.

Brondani, G. E. et al. Miniestaquia de Eucalyptus Benthamii $\times$ Eucalyptus Dunnii: sobrevivência de minicepas e produção de miniestacas em função das coletas e estações do ano. Ciência Florestal, v. 22, n. 1, p. 11-21, 2012. DOI: 10.5902/198050985075.

Cargnelutti Filho, A. et al. Dimensionamento amostral para avaliação de altura e diâmetro de mudas de Cabralea canjerana. Ciência Rural, v. 42, n. 7, p. 1204-1211, 2012. DOI: 10.1590/S010384782012000700011 .

Carmo, E. R. Produção de mudas de cedro australiano inoculadas com fungos micorrízicos arbusculares em diferentes recipientes. 2012. 57 f. (Dissertação Mestrado em Produção Vegetal) Universidade Estadual do Norte Fluminense Darcy Ribeiro, Campos dos Goytacazes.

Carneiro J. G. A. Produção e controle de qualidade de mudas florestais. Curitiba: Universidade Federal do Paraná / FUPEF; Campos: Universidade Estadual do Norte Fluminense, 1995. 451 p.

Costa, M. S. et al. Produção de mudas de timbaúba sob diferentes concentrações de efluente doméstico tratado. Irriga, v. 1, n. 1, p. 408 - 422, 2012. DOI: http://dx.doi.org/10.15809/irriga.2012v1n01. 
Cunha, A. C. M. C. M. et al. Relação do estado nutricional de minicepas com o número de miniestacas de eucalipto. Scientia Forestais, v. 36, n. 79, p. 203-213, 2008.

Davide, A. C. \& Faria, J. M. R. Viveiros florestais. In: Davide, A. C. \& Silva, E. A. A. (Ed.). Produção de sementes e mudas de espécies florestais. Lavras, MG: UFLA, 2008. p. 83-124.

Dickson, A. et al. Quality appraisal of white spruce and white pine seedling stock in nurseries. Forestry Chronicle, v. 36, n. 1, p. 10-13, 1960. DOI: $10.5558 / \mathrm{tfc} 36010-1$.

Ferreira, E. B. et al. ExpDes: experimental designs package. R package version 1.1.2. 2013. Disponível em: $<$ https://cran.r-project. org/web/packages/ExpDes/index.html>. Acesso em: 9 maio 2016.

Freitag, A. S. Frequências de irrigação para Eucalyptus grandis e Pinus elliottii em viveiro. 2007. 60 f. Dissertação (Mestrado em Engenharia Agrícola) - Universidade Federal de Santa Maria, Santa Maria, RS.

Freitas, A. F. et al. Caracterização dos viveiros florestais de Viçosa, Minas Gerais: um estudo exploratório. Desenvolvimento em Questão, v. 11, n. 22, p. 208-234, 2013.

Gomes, J. M. et al. Crescimento de mudas de Eucalyptus grandis em diferentes tamanhos de tubetes e fertilização com N-P-K. Revista Árvore, v. 27, n. 2, p. 113-127, 2003.

Gomes, J. M. Parâmetros morfológicos na avaliação de mudas de Eucalyptus grandis, produzidas em diferentes tamanhos de tubete e de dosagens de N-P-K. 2001. 126 f. Tese (Doutorado em Ciência Florestal) - Universidade Federal de Viçosa, Viçosa, MG.

Higashi, E. N. et al. Nutrição e adubação em minijardim clonal hidropônico de Eucalyptus. São Paulo: IPEF, 2002. 21 p. (IPEF. Circular técnica, 194).

Köppen, W. \& Geiger, R. Klimate der erde. Gotha: Verlag Justus Perthes. 1928.

Lopes, A. S. et al. Produtividade de minicepas de Eucalyptus urophylla $\mathrm{S}$. T Blake em função da solução nutritiva e coleta de brotações. Nativa, v. 4, n. 1, p. 44-47, 2016. DOI: 10.14583/23187670.v04n01a09.

Lougon, M. S. Crescimento de mudas de eucalipto irrigadas com água de diferentes qualidades. 2010. 56 f. Dissertação (Mestrado em Ciências Florestais) - Universidade Federal do Espírito Santo, Alegre.
Mendes, P. E. F. et al. Efluente tratado na agricultura: aspectos agronômicos e sanitários no cultivo do rabanete. Revista Brasileira de Agricultura Irrigada, v. 10, n. 1, p. 428-438, 2016.

Monteiro, D. R. et al. Efeito da aplicação de efluente doméstico tratado nos teores de micronutrientes no solo. Irriga, v. 1, n. 1, p. 40-46, 2014.

Palissari, S. C. et al. lodo têxtil e água residuária da suinocultura na produção de mudas de Eucalyptus grandis (Hill ex Maiden). Revista Engenharia Agrícola, v. 29, n. 2, p. 288-300, 2009.

Ramos, J. M. O uso da água residuárias na adubação: vantagens e limitações. Revista Científica Eletrônica de Engenharia Florestal, v. 4, n.10, p. 01-20, 2007.

Reis, E. R. et al. Período de permanência de mudas de Eucalyptus grandis em viveiro baseado em parâmetros morfológicos. Revista Árvore, v. 32, n. 5, p. 809-814, 2008. DOI: 10.1590/S010067622008000500004 .

Rezende, A. A. P. Fertirrigação do eucalipto com efluente tratado de fábrica de celulose kraft branqueada. 2003. $160 \mathrm{f}$. Tese (Doutorado em Ciências Florestais) - Universidade Federal de Viçosa, Viçosa, MG.

Ribeiro, E. A. et al. Qualidade da água de córrego em função do lançamento de efluente de abate de bovino. Revista Brasileira de Engenharia Agrícola e Ambiental, v. 17, n. 4, p. 425-433, 2013.

Ritchie, G. A. et al. Assessing plant quality. In: Landis, T. D. et al (Ed). Seedling processing, storage and outplanting. Washington, DC: US Department of Agriculture Forest Service, 2010, p. 17-81.

Rodrigues, S. B. S. Análise do uso da água em unidades de produção de mudas de eucalipto. 2007. 93 f. Dissertação (Mestrado em Engenharia Agrícola) - Universidade Federal de Viçosa, Viçosa, MG.

Santos, C. B. et al. Efeito do volume de tubetes e tipos de substratos na qualidade de mudas de Cryptomeria japonica (L. f.) D. Don. Ciência Florestal, v. 10, n. 2, p. 1-115, 2000.

Souza, J. S. et al. Produtividade de minicepas de cedro-australiano em função do teor inicial de nutrientes. Floresta, v. 45, n. 3, p. 617 624, 2015. DOI: 10.5380/rf.v45i3.36529.

Sturion, J. A. \& Antunes, J. B. M. Produção de mudas de espécies florestais. In: Galvão, A. P. M. (Ed.). Reflorestamento de propriedades rurais para fins produtivos e ambientais: um guia para ações municipais e regionais. Colombo: Embrapa Floresta, 2000. p. $125-150$. 
